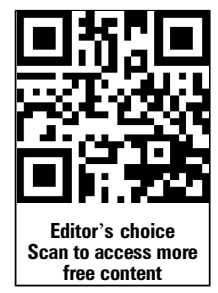

\title{
Impact of prior coronary artery bypass graft surgery on chronic total occlusion revascularisation: insights from a multicentre US registry
}

\author{
Tesfaldet T Michael, ${ }^{1,2}$ Dimitri Karmpaliotis, ${ }^{3}$ Emmanouil S Brilakis, ${ }^{1,2}$ \\ Shuaib M Abdullah, ${ }^{1,2}$ Ben L Kirkland, ${ }^{3}$ Katrina L Mishoe, ${ }^{4}$ Nicholas Lembo, ${ }^{3}$ \\ Anna Kalynych, ${ }^{3}$ Harold Carlson, ${ }^{3}$ Subhash Banerjee, ${ }^{1,2}$ William Lombardi, ${ }^{4}$ \\ David E Kandzari ${ }^{3}$
}

${ }^{1}$ Department of Internal Medicine/Cardiology, VA North Texas Healthcare System, Dallas, Texas, USA

${ }^{2}$ Department of Internal Medicine/Cardiology, University of Texas Southwestern Medical Center, Dallas, Texas, USA

${ }^{3}$ Department of Cardiology, Piedmont Heart Institute, Atlanta, Georgia, USA

${ }^{4}$ Department of Cardiology, St. Joseph Hospital, Bellingham, Washington, USA

Correspondence to Dr Emmanouil S Brilakis, Dallas VA Medical Center (111A), 4500 South Lancaster Road, Dallas, TX 75216, USA; esbrilakis@yahoo.com

Received 5 February 2013 Revised 18 March 2013 Accepted 19 March 2013 Published Online First 18 April 2013

\section{SLinked}

- http://dx.doi.org/10.1136/ heartjnl-2013-304521

To cite: Michael TT, Karmpaliotis D, Brilakis ES, et al. Heart 2013;99:15151518.

\section{ABSTRACT}

Objective To investigate the impact of prior coronary artery bypass graft (CABG) surgery on the outcomes of percutaneous coronary intervention (PCI) for chronic total occlusions (CTO).

Design Observational retrospective study.

Setting Three tertiary hospitals in the USA.

Participants 1363 consecutive patients who underwent CTO PCI between 2006 and 2011.

Main outcome measures Procedural success and inhospital complications, which were compared between patients with and without prior CABG.

Results Compared to patients without prior CABG, those with prior $C A B G$ were older, had more comorbidities, were treated more frequently with the retrograde approach $(46.7 \%$ vs $27.1 \%, p<0.001)$ and had lower technical success rates $(79.7 \%$ vs $88.3 \%$, $\mathrm{p}=0.015)$. Of the $24(1.8 \%)$ major inhospital complications, 11 occurred in patients with prior CABG and 13 in patients without prior CABG $(2.1 \%$ vs $1.5 \%$, $\mathrm{p}=0.392$ ). In multivariable analysis prior $C A B G$ was independently associated with lower technical success rate (OR $0.49,95 \%$ Cls 0.35 to $0.70, p<0.001$ ).

Conclusions In a large multicentre registry, CTO PCI was frequently performed among patients with prior $C A B G$, with higher use of the retrograde approach and similar complications but lower technical success rates compared to patients without prior CABG.

\section{INTRODUCTION}

Patients with prior coronary artery bypass graft (CABG) surgery often have complex coronary anatomy, (a) because complex coronary atherosclerosis may have led to the earlier decision for CABG, and (b) because CABG can accelerate the development of coronary atherosclerosis. ${ }^{12}$ Approximately half the patients with prior CABG undergoing coronary angiography have a coronary chronic total occlusion (CTO). ${ }^{3}$ Patients with prior CABG often develop recurrent symptoms and events due to development of saphenous vein graft disease or progression of native coronary atherosclerosis. ${ }^{4} 5$ Percutaneous coronary intervention (PCI) of native coronary arteries is preferred as revascularisation strategy among these patients, especially those with patent left internal artery bypass grafts, given the increased risk of saphenous vein graft interventions ${ }^{6}$ and the fact that repeat CABG is technically difficult, has higher mortality compared with initial CABG and provides less symptomatic improvement. $^{7}$

However, procedural success with CTO PCI is challenged among patients with prior CABG by lesion complexity that limits both antegrade and retrograde strategies. ${ }^{8}$ In the present study we sought to characterise the prevalence of CTO PCI and outcomes in this subgroup of interest, especially as it represents an increasing fraction of CTO PCI. ${ }^{9}$

\section{METHODS}

\section{Patient population}

We performed a retrospective review of the procedural and clinical records of consecutive patients who underwent CTO PCI between January 2006 and November 2011 at three US centres: St Joseph Medical Center, Bellingham, Washington, USA; Piedmont Heart Institute, Atlanta, Georgia, USA; and VA North Texas Healthcare System, Dallas, Texas, USA. The study was approved by the institutional review board of each institution.

\section{Study endpoints and definitions}

Coronary CTOs were defined as angiographic evidence of a total occlusion with thrombolysis in myocardial infarction grade 0 or grade 1 and estimated duration of at least 3 months. Estimation of occlusion duration was based upon first onset of angina, prior history of myocardial infarction in the target vessel territory or comparison with a prior angiogram. Patients were considered to have had retrograde CTO PCI if a guide wire was introduced into a collateral channel that supplied the target CTO vessel distal to the lesion.

Procedural success was defined as achievement of technical success with no inhospital major adverse cardiac events (MACE). Technical success was defined as successful CTO recanalisation with achievement of $<50 \%$ residual diameter stenosis within the treated segment and restoration of thrombolysis in myocardial infarction grade 3 antegrade flow. Inhospital MACE included any of the following adverse events prior to hospital discharge: $\mathrm{Q}$ wave myocardial infarction, recurrent angina requiring urgent repeat target vessel revascularisation with PCI or coronary bypass surgery, 
tamponade requiring pericardiocentesis or surgery, or death from any cause.

\section{Statistical analysis}

Clinical characteristics, angiographic measures and inhospital outcomes were reported using descriptive statistics. Continuous variables are presented as mean with SD and compared using the $t$ test or Wilcoxon rank-sum test, as appropriate. Categorical variables are expressed as percentages and compared using the $\chi^{2}$ or the Fisher's exact test, as appropriate. Logistic regression analysis was performed to identify predictors of technical success. Variables known to be associated with more advanced coronary artery disease and more challenging PCI (diabetes mellitus and history of myocardial infarction) as well as variables with $\mathrm{p}<0.25$ on univariable analysis (age, gender, years since start of CTO PCI, prior CABG) were included in the model. JMP V.9.0 (SAS Institute, Cary, North Carolina, USA) was used for all statistical analyses.

\section{RESULTS}

\section{Patient characteristics}

A total of 1363 consecutive patients underwent CTO PCI during the study period at three US institutions: St Joseph Medical Center, Bellingham, Washington, USA $(\mathrm{N}=728)$; Piedmont Heart Institute, Atlanta, Georgia, USA $(\mathrm{N}=360)$; and VA North Texas Healthcare System, Dallas, Texas, USA $(\mathrm{N}=275)$. All procedures were performed by experienced CTO operators at the respective institutes. A single operator (WL) performed all CTO PCI cases at St Joseph's, two operators (ESB, SB) at VA North Texas Healthcare System and five operators (DK, NL, AK, HC, DK) at Piedmont Heart Institute. The baseline clinical and angiographic characteristics of the study patients are shown in table 1 . Five hundred and eight $(37 \%)$ of patients had prior CABG, $40 \%$ had diabetes, $85 \%$ were men and the mean age was $64.5 \pm 11$ years. Fifteen per cent of patients had at least one prior failed attempt for CTO revascularisation. In most patients the target vessel was the right coronary artery (55\%), followed by the left circumflex (23\%) and left anterior descending arteries (21\%). Compared with patients

Table1 Clinical characteristics and outcomes of 1363 patients undergoing CTO PCl, classified according to whether they had undergone $\mathrm{CABG}$

\begin{tabular}{|c|c|c|c|c|}
\hline Variable & $\begin{array}{l}\text { Overall } \\
(n=1363)\end{array}$ & $\begin{array}{l}\text { With prior } \\
\text { CABG } \\
(n=508)\end{array}$ & $\begin{array}{l}\text { Without prior } \\
\text { CABG } \\
(n=855)\end{array}$ & $\begin{array}{l}p \\
\text { Value }\end{array}$ \\
\hline \multicolumn{5}{|l|}{ Clinical characteristics } \\
\hline Age (years)* & $64.5 \pm 10.8$ & $67.7 \pm 9.0$ & $63.3 \pm 10.4$ & $<0.001$ \\
\hline Men (\%) & 85.1 & 86.2 & 84.4 & 0.371 \\
\hline Hypertension (\%) & 89.0 & 92.6 & 87.2 & 0.005 \\
\hline Hyperlipidaemia (\%) & 94.0 & 96.0 & 92.6 & 0.016 \\
\hline Diabetes (\%) & 40.0 & 44.3 & 36.8 & 0.011 \\
\hline Heart failure (\%) & 24.0 & 24.7 & 23.1 & 0.540 \\
\hline $\begin{array}{l}\text { Ejection fraction } \\
<40 \%(\%)\end{array}$ & 22.0 & 21.0 & 22.5 & 0.701 \\
\hline $\begin{array}{l}\text { History of myocardial } \\
\text { infarction (\%) }\end{array}$ & 42.0 & 44.9 & 39.8 & 0.092 \\
\hline History of stroke (\%) & 6.0 & 8.0 & 4.5 & 0.015 \\
\hline Prior PCI (\%) & 42.0 & 43.4 & 40.8 & 0.337 \\
\hline
\end{tabular}

without prior $\mathrm{CABG}$, those who had prior CABG were older, had higher prevalence of coronary artery disease risk factors and more frequently had prior stroke (table1).

\section{Procedural characteristics and outcomes}

The technical and procedural success rates among the entire study population were $85.5 \%$ and $84.2 \%$, respectively. In a subset of 275 patients in whom the reason for CTO PCI failure was available, inability to cross the CTO lesion with a guidewire was the most common reason for failure (in 92.7\%) followed by failure to dilate the lesion after successful wire crossing (7.3\%). The technical success rate was lower among patients with prior CABG $(79.7 \%$ vs $88.3 \%, p=0.015)$. The retrograde approach to CTO crossing was more frequently used among patients with prior CABG (47.6\% vs $27.1 \%, \mathrm{p}<0.001$, table 2$)$. In univariate analysis, prior CABG, older age and target CTO vessel in the right coronary artery were associated with failed CTO PCI attempt. In multivariable analysis, prior CABG (OR 0.49, 95\% CI 0.35 to $0.70, \mathrm{p}<0.001)$, male gender $(\mathrm{OR}=0.51,95 \% \mathrm{CI}$ 0.28 to $0.87, \mathrm{p}=0.012)$ and years since initiation of CTO PCI at each centre $(\mathrm{OR}=1.52$ per 1 year increase, $95 \%$ CI 1.36 to 1.70 , $\mathrm{p}<0.001=0.012$ ) remained associated with technical success.

The total procedure time, fluoroscopy time and air kerma radiation exposure were higher in patients with prior CABG compared with those without. A total of 24 patients $(1.8 \%)$ experienced at least one major procedural complication. The incidence of major complications was similar in those with and without prior $\mathrm{CABG}, 2.1 \%$ vs $1.5 \%, \mathrm{p}=0.392$. Eleven major complications occurred in patients with prior CABG: deaths $(n=2$; one due to coronary perforation; one due to intracranial bleeding), donor vessel dissection $(n=1)$, perforations requiring emergency surgery or pericardiocentesis $(n=2)$, equipment entrapment $(n=1)$, transient ischaemic attack $(n=1)$ and acute myocardial infarctions $(n=4)$. Thirteen major complications occurred in patients without prior CABG: death $(n=1$; due to delayed tamponade), donor vessel dissection $(n=1)$, perforations with tamponade requiring emergency surgery or pericardiocentesis $(n=8)$, equipment entrapment $(n=1)$, stent thrombosis $(n=1)$ and acute myocardial infarction $(n=1)$.

\section{DISCUSSION}

The major findings of our study are that in a contemporary US registry: (1) patients with prior CABG represent a significant proportion of those undergoing CTO PCI, (2) patients with prior CABG were older and had more comorbidities, (3) patients with prior $\mathrm{CABG}$ were more likely to undergo retrograde CTO crossing attempts and (4) prior CABG was associated with lower technical success but similar major complication rates.

The proportion of prior CABG (37\%) among patients in our registry was higher compared with other similar registries from Japan and Europe $(5.0-15.9 \%$, table 3$) .{ }^{10-15}$ This may be due to higher use of surgical revascularisation for coronary artery disease in the USA or it could reflect local practice patterns. The high proportion of prior CABG in this series is encouraging, as it suggests that patients with prior CABG are often offered percutaneous coronary revascularisation, in spite of increased procedural complexity and lower procedural success rates.

As has been repeatedly shown in studies comparing prior CABG with non-prior CABG in various clinical settings, ${ }^{16} \mathrm{com}$ pared with patients without prior CABG, patients with prior CABG undergoing attempted CTO revascularisation were older, had more comorbidities and lower CTO PCI technical success rates. Similarly lower procedural success rates have been reported in some but not all studies. Thompson et $a l^{8}$ reported 
Table 2 Angiographic and procedural characteristics and outcomes of 1363 patients undergoing CTO PCl, classified according to whether they had undergone CABG

\begin{tabular}{|c|c|c|c|c|c|c|c|}
\hline Variable & $\begin{array}{l}\text { Overall } \\
(n=1363)\end{array}$ & $\begin{array}{l}\text { With prior CABG } \\
(n=508)\end{array}$ & $\begin{array}{l}\text { Without prior } \\
\text { CABG }(n=855)\end{array}$ & $\begin{array}{l}p \\
\text { Value }\end{array}$ & $\begin{array}{l}\text { Antegrade } \\
\text { approach }(\mathrm{n}=901)\end{array}$ & $\begin{array}{l}\text { Retrograde } \\
\text { approach }(n=462)\end{array}$ & $\begin{array}{l}p \\
\text { Value }\end{array}$ \\
\hline СТО target vessel & & & & $<0.001$ & & & $<0.001$ \\
\hline Right coronary artery (\%) & 55 & 56.2 & 54.7 & & 48.9 & 66.4 & \\
\hline Circumflex (\%) & 23 & 27.4 & 20.1 & & 25.6 & 17.8 & \\
\hline Left anterior descending artery (\%) & 21 & 14.2 & 25.0 & & 24.5 & 14.7 & \\
\hline Left main/bypass graft (\%) & 1.0 & 2.2 & 0.2 & & 0.9 & 1.1 & \\
\hline Prior failed attempt for CTO PCI (\%) & 15 & 13.0 & 16.6 & 0.820 & 13.9 & 17.1 & 0.123 \\
\hline Antegrade wire escalation attempt (\%) & 96.7 & 94.2 & 97.5 & 0.206 & 100 & 85.9 & $<0.001$ \\
\hline Antegrade dissection/re-entry attempt (\%) & 28.9 & 29.4 & 28.7 & 0.912 & 23.2 & 48.4 & $<0.001$ \\
\hline Retrograde approach attempt (\%) & 34 & 46.7 & 27.1 & $<0.001$ & NA & NA & \\
\hline $\begin{array}{l}\text { Collateral vessel used for retrograde approach } \\
(\%)(n=462)\end{array}$ & & & & $<0.001$ & & & NA \\
\hline Septal (\%) & 68 & 52.8 & 77.6 & & NA & 68 & \\
\hline Epicardial (\%) & 24 & 31.0 & 22.4 & & NA & 24 & \\
\hline Bypass graft (\%) & 8 & 17.2 & NA & & NA & 8 & \\
\hline Technical success rate $(\%)$ & 85.5 & 79.7 & 88.3 & $<0.001$ & 87.8 & 80.9 & $<0.001$ \\
\hline Procedural success rate (\%) & 84.2 & 78.1 & 87.2 & $<0.001$ & 87.1 & 78.5 & $<0.001$ \\
\hline Total procedure time $(\mathrm{min})^{*}$ & $113 \pm 61$ & $125 \pm 65$ & $106 \pm 58$ & $<0.001$ & 87.8 & 80.9 & $<0.001$ \\
\hline Total fluoroscopy time $(\mathrm{min})^{*}$ & $42 \pm 29$ & $49 \pm 30$ & $38 \pm 27$ & $<0.001$ & 87.1 & 78.5 & $<0.001$ \\
\hline Total air kerma radiation exposure (Gray)* & $4.7 \pm 3.8$ & $5.5 \pm 5.0$ & $4.3 \pm 3.0$ & 0.003 & $3.7 \pm 3.8$ & $6.4 \pm 3.2$ & $<0.001$ \\
\hline Total contrast volume $(\mathrm{ml})^{*}$ & $294 \pm 158$ & $296 \pm 156$ & $293 \pm 160$ & 0.762 & $268 \pm 146$ & $343 \pm 168$ & $<0.001$ \\
\hline Inhospital major complication, \% & 1.8 & 2.1 & 1.5 & 0.392 & 0.89 & 3.46 & 0.001 \\
\hline
\end{tabular}

${ }^{*}$ Mean \pm SD.

CABG, coronary artery bypass graft surgery; CTO, chronic total occlusion; NA, not applicable; PCl, percutaneous coronary intervention.

that patients with prior CABG who required CTO PCI were more likely to be treated by a retrograde operator than by a non-retrograde operator $(35.5 \%$ vs $12.9 \%, \mathrm{p}<0.001)$.Although Galassi et $a l^{11}$ reported no significant association between presence of prior CABG and procedural success of CTO PCI, the proportion of prior CABG was higher in the failed PCI group in several CTO PCI registries. ${ }^{10} 13-15$

In a large, multinational CTO registry of 1791 patients who underwent 1852 CTO PCIs, prior CABG was present in $20.9 \%$ of patients in the failed PCI group versus $13.6 \%$ in the successful PCI group $(\mathrm{p}<0.01) .{ }^{10}$ Similarly, Jones et $a l^{15}$ reported higher proportion of prior CABG in the failed CTO PCI group compared with those who had successful CTO recanalisation (16.5\% vs 7.4\%, p<0.001). Teramoto et $a l^{17}$ analysed 1807 CTO PCI procedures performed at the Toyohashi Heart Center in Japan and reported initial angiographic success in 70\%
$(156 / 224)$ of patients with prior CABG versus $81 \%$ $(1279 / 1583)$ in patients without prior CABG.

The lower CTO PCI success rates among patients with prior CABG are likely a reflection of the increased technical difficulty of performing intervention in such patients. CABG can accelerate the progression of coronary atherosclerosis. ${ }^{12}$ Prior CABG is associated with longer duration of coronary occlusion and more pronounced calcification making CTO PCI more technically challenging. $\mathrm{CABG}$ may also cause tenting and distortion of the native coronary arteries hindering CTO crossing attempts. Patients with prior CABG undergoing CTO PCI often have severe tortuosity and blunt stump (although these variables are not systemically collected in our study). Moreover, patients may often have several CTOs or diffusely diseased vessels. On the other hand bypass grafts can be used as conduits (even when occluded) ${ }^{6} 18$ that can facilitate CTO intervention via the retrograde approach. ${ }^{19}$ On the other hand

Table 3 Summary of large contemporary CTO PCI registry publications that reported outcomes for the subgroup of patients with prior CABG

\begin{tabular}{|c|c|c|c|c|c|c|c|c|c|c|}
\hline Author & Year & $\begin{array}{l}\text { N (CTO } \\
\text { lesions) }\end{array}$ & $\begin{array}{l}\text { Prior } \\
\text { CABG, } \\
(\%)\end{array}$ & $\begin{array}{l}\text { Prior CABG in } \\
\text { successful PCI } \\
\text { group }(\%)\end{array}$ & $\begin{array}{l}\text { Prior CABG in } \\
\text { unsuccessful PCI } \\
\text { group }(\%)\end{array}$ & $\begin{array}{l}\text { Overall, } \\
\text { retrograde } \\
(\%)\end{array}$ & $\begin{array}{l}\text { Overall, } \\
\text { technical } \\
\text { Success (\%) }\end{array}$ & $\begin{array}{l}\text { Overall, major } \\
\text { complications } \\
(\%)\end{array}$ & $\begin{array}{l}\text { Overall, } \\
\text { fluoroscopy } \\
\text { time (min) }\end{array}$ & $\begin{array}{l}\text { Overall, } \\
\text { contrast } \\
\text { use }(\mathrm{ml})\end{array}$ \\
\hline Olivari et al ${ }^{13}$ & 2003 & 376 & 5.0 & 4.5 & 6.9 & NR & 77.2 & 5.1 & NR & NR \\
\hline Rathore et $a l^{14}$ & 2009 & 904 & 12.6 & 11.9 & 17.7 & 17 & 87.5 & 1.9 & NR & NR \\
\hline Morino et $a l^{12}$ & 2010 & 528 & 9.6 & NR & NR & 26 & 86.6 & NR & $45(1-301)^{*}$ & $293(53-1,097)^{*}$ \\
\hline Mehran et $a l^{10}$ & 2011 & 1791 & 15.9 & 13.6 & 20.9 & NR & 68.0 & NR & NR & $448 \pm 229$ \\
\hline Galassi et $a l^{11}$ & 2011 & 1983 & 14.6 & NR & NR & 14 & 82.9 & 1.8 & $42.3 \pm 47.4 \dagger$ & $313 \pm 184 \dagger$ \\
\hline Jones et $a l^{15}$ & 2012 & 836 & 10.2 & 16.5 & 7.4 & NR & 69.6 & 2.3 & NR & NR \\
\hline Present study & 2012 & 1363 & 37.0 & 35.0 & 50.8 & 34 & 85.5 & 1.8 & $42 \pm 29 t$ & $294 \pm 158 \dagger$ \\
\hline
\end{tabular}


CTO PCI may be particularly attractive in patients with prior CABG, because treatment of failing saphenous vein bypass grafts can be challenging with high rates of periprocedural myocardial infarction and subsequent failure and occlusion, even when using drug eluting stents. ${ }^{4} 20$

The higher use of the retrograde approach among patients with prior CABG could be related to (1) the complexity of CTO lesion in the patient requiring more aggressive crossing techniques after wire escalation crossing attempts fail and (2) the availability of bypass grafts, that can act as retrograde conduits (whether they are patent or occluded) in patients with prior CABG. ${ }^{18}{ }^{19}$ Use of a vein graft as a retrograde channel in CTO PCI has been reported in 3.1-8.2\% of cases. ${ }^{8} 92122$ Moreover, (3) retrograde CTO PCI may be safer in patients with prior CABG (especially if epicardial collaterals are used) because pericardial adhesions may reduce the likelihood of tamponade in case of collateral vessel perforation (although tamponade can still occur, as shown in the present and prior studies). ${ }^{23-25}$

Our study has several potential limitations. First, the data were analysed retrospectively, although they were collected prospectively. Second, the coronary angiograms were not reviewed by an angiographic core laboratory and no adjudication of the clinical outcomes was performed by a clinical events committee, although adjudication would be unlikely to change the main adverse outcomes, such as death, emergency CABG and the need for urgent pericardiocentesis. Third, systematic measurement of cardiac biomarkers after CTO PCI was not performed, limiting the detection of subclinical myocardial infarction, although the latter may have limited clinical implications. ${ }^{26}$

In summary, our study suggests that in selected US programs, CTO percutaneous recanalisation was frequently performed in patients with prior $C A B G$, often required use of retrograde crossing and was associated with lower technical success but similar complication rates.

Contributors All authors have made substantial contribution for the intellectual content of the manuscript and have given final approval for publication.

Competing interests TTM: Supported by Cardiovascular Training Grant from the National Institutes of Health Award Number T32HL007360. DK: speaker bureau, Abbott Vascular and Medtronic; consultant, Bridgepoint Medical. ESB: Speaker honoraria from St Jude Medical, Terumo and Bridgepoint Medical/Bostoc Scientific; research support from Guerbet; spouse is an employee of Medtronic. NL: speaker bureau: Medtronic; advisory board Abbott Vascular and Medtronic. SB: Speaker honoraria from St. Jude Medical, Medtronic, and Johnson \& Johnson, Boehinger, Sanofi, Mdcare Global; research support from Boston Scientific and The Medicines Company. DEK: Research/grant support from Abbott Vascular, Boston Scientific Corporation and Medtronic CardioVascular; Consultant, Boston Scientific Corporation and Medtronic CardioVascular; Institutional educational grant from Bridgepoint Medical/Boston Scientific Corporation. WL: consultant for Abbott Vascular, Bridgepoint Medical, Medtronic; speaker honoraria from Abbott Vascular, Medtronic and Terumo; equity, Bridgepoint Medical

Ethics approval The institutional review board of each institution.

Provenance and peer review Not commissioned; externally peer reviewed.

\section{REFERENCES}

1 Hwang MH, Meadows WR, Palac RT, et al. Progression of native coronary artery disease at 10 years: insights from a randomized study of medical versus surgical therapy for angina. J Am Coll Cardiol 1990;16:1066-70.

2 Rupprecht HJ, Hamm C, Ischinger T, et al. Angiographic follow-up results of a randomized study on angioplasty versus bypass surgery (GABI trial). GABI Study Group. Eur Heart J 1996;17:1192-8.

3 Fefer $\mathrm{P}$, Knudtson ML, Cheema AN, et al. Current perspectives on coronary chronic total occlusions: the Canadian Multicenter Chronic Total Occlusions Registry. J Am Coll Cardiol 2012;59:991-7.
4 Lee MS, Park SJ, Kandzari DE, et al. Saphenous vein graft intervention. JACC Cardiovasc Interv 2011;4:831-43.

5 Brilakis ES, Rao SV, Banerjee S, et al. Percutaneous coronary intervention in native arteries versus bypass grafts in prior coronary artery bypass grafting patients: a report from the National Cardiovascular Data Registry. JACC Cardiovasc Interv 2011;4:844-50.

6 Abdel-Karim AR, Banerjee S, Brilakis ES. Percutaneous intervention of acutely occluded saphenous vein grafts: contemporary techniques and outcomes. I Invasive Cardiol 2010;22:253-7.

7 Fitzgibbon GM, Kafka HP, Leach AJ, et al. Coronary bypass graft fate and patient outcome: angiographic follow-up of 5,065 grafts related to survival and reoperation in 1,388 patients during 25 years. J Am Coll Cardiol 1996;28:616-26.

8 Thompson CA, Jayne JE, Robb JF, et al. Retrograde techniques and the impact of operator volume on percutaneous intervention for coronary chronic total occlusions an early U.S. experience. JACC Cardiovasc Interv 2009;2:834-42.

9 Karmpaliotis D, Michael TT, Brilakis ES, et al. Retrograde coronary chronic total occlusion revascularization: procedural and in-hospital outcomes from a multicenter registry in the United States. JACC Cardiovasc Interv 2012;5:1273-9.

10 Mehran R, Claessen BE, Godino C, et al. Long-term outcome of percutaneous coronary intervention for chronic total occlusions. JACC Cardiovasc Interv 2011:4:952-61.

11 Galassi AR, Tomasello SD, Reifart N, et al. In-hospital outcomes of percutaneous coronary intervention in patients with chronic total occlusion: insights from the ERCTO (European Registry of Chronic Total Occlusion) registry. Eurolntervention 2011:7:472-9.

12 Morino Y, Kimura T, Hayashi Y, et al. In-hospital outcomes of contemporary percutaneous coronary intervention in patients with chronic total occlusion insights from the J-CTO Registry (Multicenter CTO Registry in Japan). JACC Cardiovasc Interv 2010:3:143-51.

13 Olivari Z, Rubartelli P, Piscione F, et al. Immediate results and one-year clinical outcome after percutaneous coronary interventions in chronic total occlusions: data from a multicenter, prospective, observational study (TOAST-GISE). J Am Coll Cardiol 2003;41:1672-8.

14 Rathore S, Matsuo H, Terashima M, et al. Procedural and in-hospital outcomes after percutaneous coronary intervention for chronic total occlusions of coronary arteries 2002 to 2008: impact of novel guidewire techniques. JACC Cardiovasc Interv 2009;2:489-97.

15 Jones DA, Weerackody R, Rathod K, et al. Successful recanalization of chronic total occlusions is associated with improved long-term survival. JACC Cardiovasc Interv 2012:5:380-8.

16 Brilakis ES, de Lemos JA, Cannon CP, et al. Outcomes of patients with acute coronary syndrome and previous coronary artery bypass grafting (from the Pravastatin or Atorvastatin Evaluation and Infection Therapy [PROVE IT-TIMI 22] and the Aggrastat to Zocor [A to Z] trials). Am J Cardiol 2008;102:552-8.

17 Teramoto $\mathrm{T}$, Ito $\mathrm{T}$, Tsuchikane $\mathrm{E}$, et al. Prior coronary artery bypass grafting diminishes the initial success rate of percutaneous coronary intervention in chronic total occlusion of a native coronary artery. JACC 2012;59:E104.

18 Brilakis ES, Banerjee S, Lombardi WL. Retrograde recanalization of native coronary artery chronic occlusions via acutely occluded vein grafts. Catheter Cardiovasc Interv 2010;75:109-13.

19 Michael TT, Banerjee S, Brilakis ES. Role of internal mammary artery bypass grafts in retrograde chronic total occlusion interventions. I Invasive Cardiol 2012;24:359-62.

20 Brilakis $\mathrm{ES}$, Lichtenwalter $\mathrm{C}$, de Lemos JA, et al. A randomized controlled trial of a paclitaxel-eluting stent versus a similar bare-metal stent in saphenous vein graft lesions the SOS (Stenting of Saphenous Vein Grafts) trial. J Am Coll Cardiol 2009;53:919-28

21 Kimura M, Katoh O, Tsuchikane E, et al. The efficacy of a bilateral approach for treating lesions with chronic total occlusions the CART (controlled antegrade and retrograde subintimal tracking) registry. JACC Cardiovasc Interv 2009;2:1135-41.

22 Rathore $\mathrm{S}$, Katoh $\mathrm{O}$, Matsuo $\mathrm{H}$, et al. Retrograde percutaneous recanalization of chronic total occlusion of the coronary arteries: procedural outcomes and predictors of success in contemporary practice. Circ Cardiovasc Interv 2009:2:124-32.

23 Brilakis ES, Karmpaliotis D, Patel V, et al. Complications of chronic total occlusion angioplasty. Interven Cardiol Clin 2012:1:373-89.

24 Lowe R, Hammond C, Perry RA. Prior CABG does not prevent pericardial tamponade following saphenous vein graft perforation associated with angioplasty. Heart 2005;91:1052

25 Marmagkiolis K, Brilakis ES, Hakeem A, et al. Saphenous vein graft perforation during percutaneous coronary intervention: a case series. I Invasive Cardiol 2013;25:157-61.

26 Prasad A, Herrmann J. Myocardial infarction due to percutaneous coronary intervention. N Engl J Med 2011;364:453-64. 